\title{
REPORTE DE CUATRO CASOS DE LA ENFERMEDAD DE VOG $\Gamma$ - KOYANAGI - HARADA
}

\author{
César A. GonzÁlez*
}

Hasta el momento sólo 20 casos de la enfermedad Harada y no más de 70 casos del Sindrome Vogit-Koyamagi han sido comunicados en la literatura revisada. Estamos de acuerdo con la gran mayoría de los investigadores en que estas dos entidades son una sola. Probablemente tienen una misma etiología, pero ditieren primariamente en el grado de severidad, localización, intensidad del proceso y magnitud de evidencia clínica.

En muchos de los casos reportados se hace énfasis en el hecho de que casos clasificados como enfermedad de Harada, muestran extenso compromiso del segmento posterior en contraste con el Sindrome de Vogt-Koyanagi, que enseña como principal defecto mayor lesión en el segmento anterior y menor en el posterior.

La oparente rareza del proceso; la atípica distribución geográfica; el hecho de presentarse en diferentes grupos raciales; en tendencia a presentarse en infantes y adultos; y su bien conocida evidencia clínica, nos permite arribar a una serie de discriminaciones a la vez que a tratar de especular sobre este síndrome particular o quizás enfermedad no bien conocida.

Los primeros reportes de este proceso indicabon una tendencia racial.

Nuestros esiudios y algunas otras publicaciones nos inclinan a pensar que este proceso patológico no es exclusivo de las razas de alta pigmentación.

(*) Profesor Asociado a cargo de la Asignatura de Oftalmología, Facultad de Medicina de la Universidad Nacional Mayor de San Marcos. 
Ante las bases de nuestras observaciones y los estudios de otros autores, creemos que el proceso tiene barse inflamatoria y no componente alérgico.

Las bien conocidas manifestaciones encefálicas que abren el cuadro clínico, son más compatibles con un proceso infeccioso que alérgico; su repercusión en el tracto uveal y la apariencia del fondo de ojo sugieren infiamación; de otro lado, la p'eocitosis en el líquido céfaloraquídeo es de tipo infeccioso. Su cronicidad, así como la evolución clínica, es, médicamente hablando, más compatible con infección que alergia. Es posible que un virus con tendencia neurotrópica actúe en el proceso, ya sea directamente o a través de su endotoxina. Decimos neurotrópico por cuanto es el sistema nervioso central el que aparentemente es el primero en ser envuelto en el proceso. Sabido es que son los plexos coroideos los encargados de la producción del líquido céfaloraquídeo y deseamos creer que la "lesión inicial" es en ese lugar; de allí las manifestaciones de irritación meníngea. En alguna forma, el líquido cerebro-espinal compromete el tejido mesodermal del segmento posterior del ojo para luego, por extensión, mostrar la típica apariencia oftalmoscópica y, por continuidad, la invasión al segmento anterior. Interpretamos sus manifestaciones entodérmicas (Poliosis vitíligo) a través de los vasos sanguíneos mesodérmicos. Este fenómeno mórbido es de difícil explicación.

Pensamos que esta entidad clínica podría ser agrupada en un solo nombre que indicaría su componente clínico envolutivo, el síndrome En. céfalo-Uveo-Dermatosis que indicaría el curso de este proceso.

\section{DESCRIPCION DE LA CASUISTICA}

A continuación presentamos los principales datos de las cuatro enfermas que constituyen la casuística de este trabajo.

\section{A S U I S T I C A}

Caso No 1.- (Historia No E. 55631). - Paciente blanca, de 50 años de edad; ocupación su casa, casada. En abril 28 de 1957 es despertada con intenso dolor de cabeza tipo latido y que comprometía en y alrededor del ojo izquierdo. Tres dias después ojos rojos, epífora y fotofobia bilateral. En mayo 3, no puede leer los títulos de los diarios; el 10 de mayo del mismo año es vista por el Oftalmólogo quien encuentra borrosos los discos ópticos, bilateralmente, se le indicó atropina al $1 \%$, Terracortril, Metacorten $20 \mathrm{~mm}$. al dia y Cloromicetina 1 gramo diariamente. 
En Mayo 21 del mismo año fué admitida al Hospital.

Historia familiar: negativa por enfermedad ocular o del sistema nervioso central.

Antecedentes Patológicos.- Posible fiebre tifoidea en la infancia. Apendicectomia en 1957. Traumatismo craneano con pérdida de conciencia pero sin secuelas en 1942.

Revisión de Sistemas.- Dolor de cabeza infrecuentes, excepto durante la enfermedad presente. No existen náuseas, vómitos, durante este periodo.

Examen Físico.- Presión arterial 176/88. Pulso 76; respiraciones 18'.

Oído, naríz y garganta: negativo. Las amígdalas pequeñas. Ojos: agudeza visual: O.D. $20 / 100$ y O.S. $20 / 60$ con la mejor corrección. Los M.E.O. libres de parálisis o paresia. Pupilas iguales, simétricas, con reacciones a la 1 . a.c. normales.

Reporte de cuatro casos de la enfermedad de Horada y del Sindrome de Vogt-Koyanogi

\begin{tabular}{|c|c|c|c|c|c|c|c|c|}
\hline \multirow[b]{2}{*}{ Raza } & \multirow[b]{2}{*}{ Edad } & \multirow[b]{2}{*}{ Cetalea } & \multicolumn{3}{|c|}{ Dlsminuclón de } & \multirow[b]{2}{*}{ Vitilugo } & \multicolumn{2}{|c|}{ Desprendim. } \\
\hline & & & Uveitss & Visión & Alopecta & & Disacusia & Seroso \\
\hline BLANCA & 50 & $x$ & $x$ & $x$ & - & - & $x$ & $x$ \\
\hline NEGRA & 36 & $x$ & $x$ & $x$ & - & - & - & $x$ \\
\hline BLANCA & 33 & $x$ & $x$ & $x$ & 一 & 一 & - & $x$ \\
\hline NEGRA & 30 & $x$ & $x$ & $x$ & $x$ & $x$ & $x$ & $x$ \\
\hline
\end{tabular}

Realizada la dilatación pupilar los fondos oculares fueron estudiados: en O. D. edema macular presente. El nervio óptico es normal en color pero sus márgenes borrosos. Se aprecia bandas a tensión siguiendo las fibras nerviosas .Las venas discretamente congestionadas. No exudados o hemorragias. En la periferia del lado nasal se aprecia separación coriotineal. En O.S. el disco se veía pobremente, sus márgenes eran indistinguibles. Apreciábamos edema generalizado con dilatación venosa. Separación corioritineal que se extendía de posición 3 a 9 inferiormente.

Biomicroscopia: O.D. cornea normal. La cámara anterior clara, se aprecia evidencia de sinequias posteriores rotas, y pigmento residual en la cara 
anterior del cristalino. En O.S. cornea normal. Una + de contenido proteico en la cámara anterior.

El resto del examen físico era enteramente normal.

Examen de Laboratorio.- Hemoglobina $10.4 \mathrm{grm}$. Hematocrito 36.5. Leucocitos 8,$400 ; 56$ segmentado; abastonados $1 ; 32$ pequeños linfocitos; dos grandes Iinfocitos; 9 monocitos. Las plaquetas fueron normales. Velocidad de sedimentación corregida $2 \mathrm{~mm}$. Examen de orina normal. Serológicas negativas. N. P. N. 26; ácido úrico 2.1. Glicemia 103. Cloro en suero 101.2. Sodio 140. Potasio 4.3. Ca. 8.8. Fósforo 3.6. Proteínas totales 6.2. A.G 3.23. Colesterol 231. Radiografía de Tórax normal. Radiografía de senos paranasales mostró discreto velamiento del seno maxilar. Los etmoidales y los frontales claros.

A la admisión la paciente fué puesta en dieta hiposódica de $800 \mathrm{~mm}$.; metacorten $20 \mathrm{~mm}$. al día; $1 \%$ de atropina 1 gota en cada ojo 3 veces al día.

El audiograma mostró pequeña pérdida perceptiva auditoria del oído izquierdo al nivel de 6,000 ciclos.

Paciente fué vista en consulta por neurólogo quien reporta: no enfermedad al sistema nervioso central.

La punción lumbar mostró presión inicial $80 \mathrm{~mm}$. de agua y la final 40 mm. de agua. El líquido céfalo raquídeo fué cristal de roca. No leucocitos y 6 hematies. Pandy negativo.

La perimetría mostró moderada contracción de ambos ojos, pero, más marcada en el izquierdo. A la tangente el ojo derecho enseñaba agrandamiento del punto ciego y un escotoma central grande. A su control mostraba mejoría del escotoma central persistiendo el agrandamiento del punto ciego. El 28 de Mayo de 1957 su visión corregida se encontraba en 20/30 en O.D. y $20 / 200$ en O.S. El 29 fué dada de alta aconsejándose se continuara con $5 \mathrm{~mm}$. al día de Meticorten, atropina 1 gota 3 veces al día, Neo-Delta-Cortef una gota en cada ojo 4 veces al día y Neo-Cortef ungüento en ambos ojos a la hora de dormir.

En Agosto $1^{\circ}$ de 1957 aprecia que la agudeza visual ha disminuído desde que los esteroides fueron descontinuados. Entonces, su visión en O.D. se encontraba $20 / 70$ y O.S. 20/100 mínimo edema de ambas máculas. Línea pigmentaria en la retina se observaba, lo que nos indicaba sitio del desprendimiento de retina. Se apreciaba asimismo incremento del contenido proteico del acuoso con rara queratitis precipitada en ojo derecho, la paciente fué puesta en forma vigorosa con esteroides local y sistémico.

No encontramos mayores reportes.

Caso No 2.- Paciente de 36 años, negra, de ocupación su casa; admitida al hospital el 20 de Julio de 1959 quejándose de rápida disminución visual de la agudeza de ambos ojos. Gozaba de buena salud hasta hace dos semanas de su admisión, tiempo éste en que nota un dolor de cabeza bifrontal, bitemporal, con sensación nauseosa pero no vómito, no había otra sintomatología deficitaria del sistema nervioso central. Visión borrosa bilateral; ojos rojos pero niega dolor. Fué vista por colega quien indica esteroides y atropina. Como quiera que su condición ocular continuase empeorando es referida al hospital. 
Antecedentes Personales Patológicos.- No hay nada en su historia personal digna de mención.

Examen Físico.- Lo único positivo al examen clínico estuvo limitado a los ojos y el examen dental que demostró una severa gingivitis y piezas cariadas.

Su visión se encontraba en $20 / 40$ no corregible.

El examen de la apariencia externa demostró una mínima congestión ciliar bilateral, los M.E.O. ful y coordinados. Las pupilas se encontraban en amplia midriasis, regulares y fijas, dilatadas por la instilación de atropina.

Los fondos oculares mostraban en forma bilateral, marcada neuroretinitis con hiperamia y edema de los discos, dilatación venosa y edema difuso-retineal que comprometía la región macular y la periferia de todos los cuadrantes. Se apreciaba pequeñas hemorragias superficiales cerca de ambas papilas ópticas. En este primer examen no se apreció separación retineal.

A lámpara de hendiaura se observaba pequeñas queratitis precipitadas, no pigmentadas, en el endotelio corneal, bilateralmente.

Una + de contenido celular y proteico en la cámara anterior. No existía sinequias posteriores. En el iris derecho veíamos un nódulo Koeppe y en iris izquierdo dos nódulos de Busacca. Los cristalinos se mostraban claros. En el espacio-retro-lenticular moderada cantidad de células, también bilateralmente. La presión intraocular se registró 12.2 O.U. (Schiotz). La perimetría fué normal. La tangente enseñaba un escotama central de $15{ }^{\circ}$ en ambos ojos, usamos un objetivo de $3 \mathrm{mim}$. blanco.

Examen de Laboratorio.- Hemoglobina 12.3 grms. Leucocitos 11.800. Polimorfonucleares 91. Linfocitos 8, Monocitos 1. El examen completo de orina fué normal. Sodio 132. Potasio 4.1, Cloro 99.3. Co2 combinado 26.1. Calcio 8.8 Fósforo 2.6 Proteínas totales 7.2. Albúmina 3.2. Glubulina 4. B.U.N. 12. Tiempo de protrombina 13". Tiempo de sangría y coagulación normales. Serología negativo, transaminasa y proteina sero-reactiva negativa. Radiografía de cráneo, tórax y senos paranasales, normales.

Curso en el Hospital.- Con el diagnóstico de enfermedad Harada la paciente fué admitida. Se implantó tratamiento con Neo-De-Cortef solución $0.25 \%$ una gota en cada ojo cada hora. Atropina $1 \% 3$ veces al día. Dieta hiposódica de $600 \mathrm{~mm}$. x 40 unidades de A.C.T.H. en 1,000 cm. de dextrosa en agua a razón de $50 \mathrm{~cm}$. por hora lo cual se administró por 4 días; al cabo de los cuales se dió $1.5 \mathrm{~mm}$. de decadrón 4 veces al día. En su tercer día de hospitalización una extensa área de separación retinal fué observada en el ojo derecho; la misma situación al día siguiente en el ojo contralateral. La paciente fué vista en consulta en el Servicio de Urologia y Otorrinolaringología sin que se pudiese detectar foco de infección. Los audiogramas fueron reportadas como normales. La consulta dental reveló varias piezas cariadas y gingivitis crónica. La consulta médica no evidenció enfermedad granulomatosa. Biopsia hepática sin que se tuviese demostrar compromiso granulomatoso en el estudio histológico, fué pues negativo para sarcoidosis y tuberculosis. La punción lumbar enseñó dinámica normal. $83 \mathrm{~mm} . \%$ de proteínas. Pandy negativa. Serología negativa. Oro coloidal 2233321000 y existían 200 células a predominio de linfocitos. La punción fué repetida 2 días después y en- 
señó 150 linfocitos presentes. El estudio con tinta china fué negativo. Estudios de L.C.R. para bacterias hongos y virus fueron negativos. La consulta neurológica coincide con nuestro diagnóstico de Uveo-encefalitis. El electroencéfalo fue normal. La prueba cutánea con tuberculina 1/100 negativa. Los estudios de toxoplasma en suero también negativo. El estudio de las uveitis con pruebas cutáneas aconsejado por el Instituto Nacional fué sin significancia.

A los 6 días de admitida el examen de fondo de ojo mostró que la sepa. ración de las retinas fué retornando a la normalidad y que la hiperemia $y$ el edema de los nervios habia disminuído. Persistía el edema macular. La vi, sión con el agujero estenopeico se encontraba en 20/100 en O.U. Los campos visuales enseñaban mejoria del escotoma central y sólo una pequeña indentación de los cuadrantes superiores en los estudios de la perimetría en contraste con las previas separaciones notadas de la separación inferior.

Para el 28 de Julio su visión estaba 20/60-2 a O.D. con el agujero estenopéico. La tensión ocular 12.2 en O.U. La hiperemia de los discos era pequeña pero, persistía la dilatación venosa y el edema macular pero, en esta oportunidad la retina se encontraba en su posición normal. Una notable disminución de las queratitis precipitada y el fenómeno de Tindal también. Una que otra célula en el espacio retrolenticular.

La paciente fué dada de alta el 4 de Agosto de 1959 con visión en O.D. $20 / 40$ y O.S. 20/50. La presión intraocular 17.3 en $0 . U$. No actividad en el acuoso. No se apreciaban nódulos en el iris. Fué aconsejada continuar con $1 \mathrm{~mm}$. de Decadrón 4 veces al día. Neo-De-Cortef. 1 gota 4 veces al día y Atropina una 3 veces en ambos ojos. Al dia siguiente fué readmitida, en esta oportunidad, al Servicio de Medicina con el diagnóstico de sindrome agudo cerebral secundario a telapia por esteroides. Fué aislada en los primeros 5 días de su admisión y su conducta paranoide fué desapar'eciendo a medida que se disminuia la terapia sistemática de esteroides. Sedación con tranquilizadores e hidrato de cloral. Estudio de laboratorio en esta oportunidad no hubo cambios significantes. El L.C.R. mostró de la normalidad de las dinámicas y proteinas y sólo una célula linfocitica. El 7 de Agosto su agudeza visual se encontraba en 20/40 en o.U. Minimo era el edema de los nervios ópticos. Casi completa la reabsorción del edema macular. I desaparición del escotoma central cuando usamos un objetivo de $2 \mathrm{~mm}$.

Para el 8 de Agosto se encontraba libre de sintomatología sistémica y ocular. Su visión en O.D. 20/40 y O.S. $20 / 25$ no corregible. La tensión ocular normal. La biomicroscopia mostraba mínimo contenido protéico y sólo algunas queratitis precipitada. No habia nódulos en el iris. El fondo ocular con edema residual en ambas regiones maculares. Las venas persistian dilatadas. Las retinas en posición normal. Aconsejamos continuar con esteroide y atropina local.

Caso No 3.- (H. E. NP 84282). Paciente de 33 años de edad, blanca, ocupación su casa, casada, admitida al Hospital el 5 de Setiembre de 1958. Estuvo asintomática hasta Julio 1958 en que comienza a sentir dolores de cabeza diarios bifrontales y ocasionalmente con radiación occipital los que dura- 

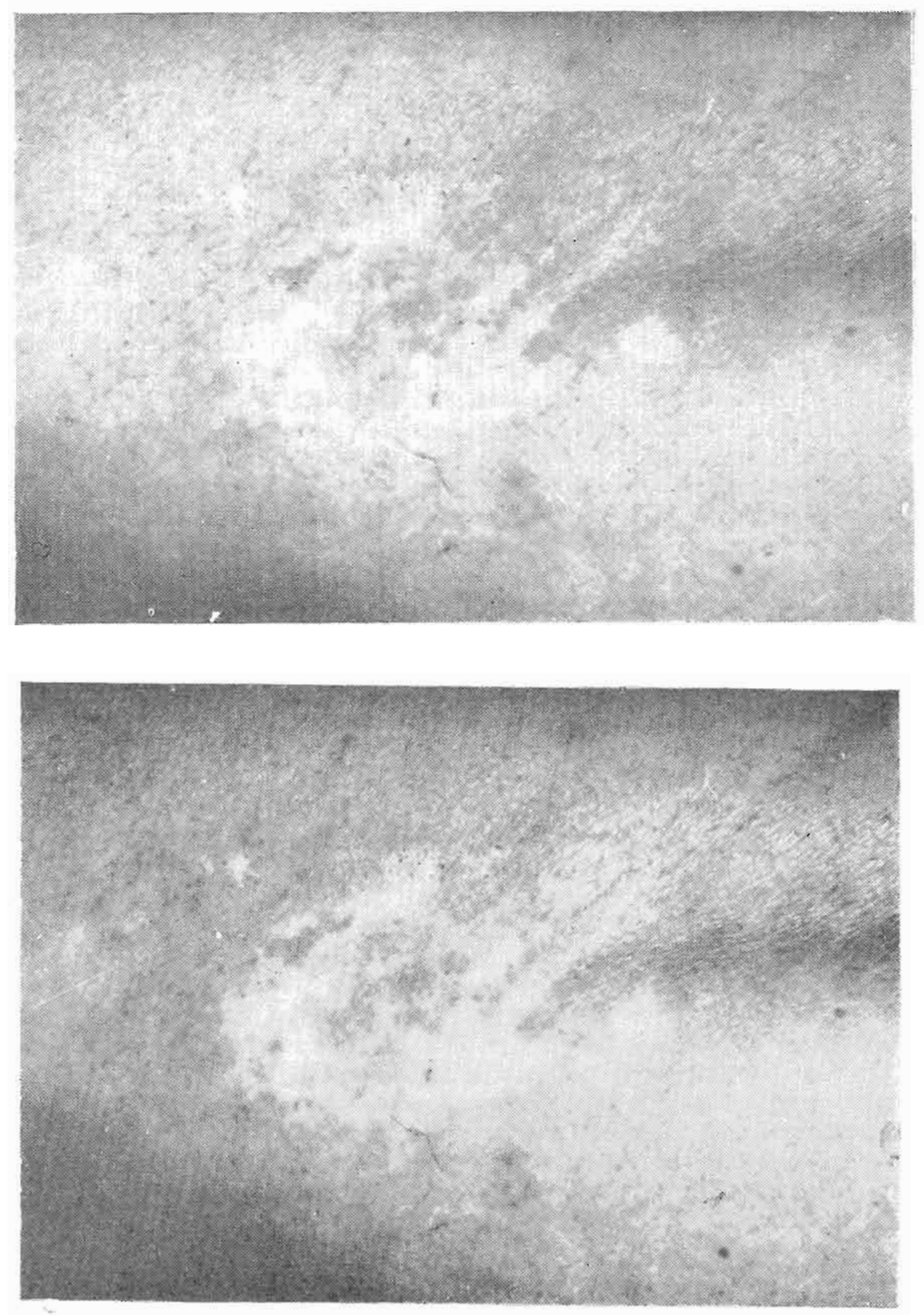

Fotọ No 1 y 2:- Arẹos de Vitiligo, șimẹtriças, bilatẹroles de antebrazo: 


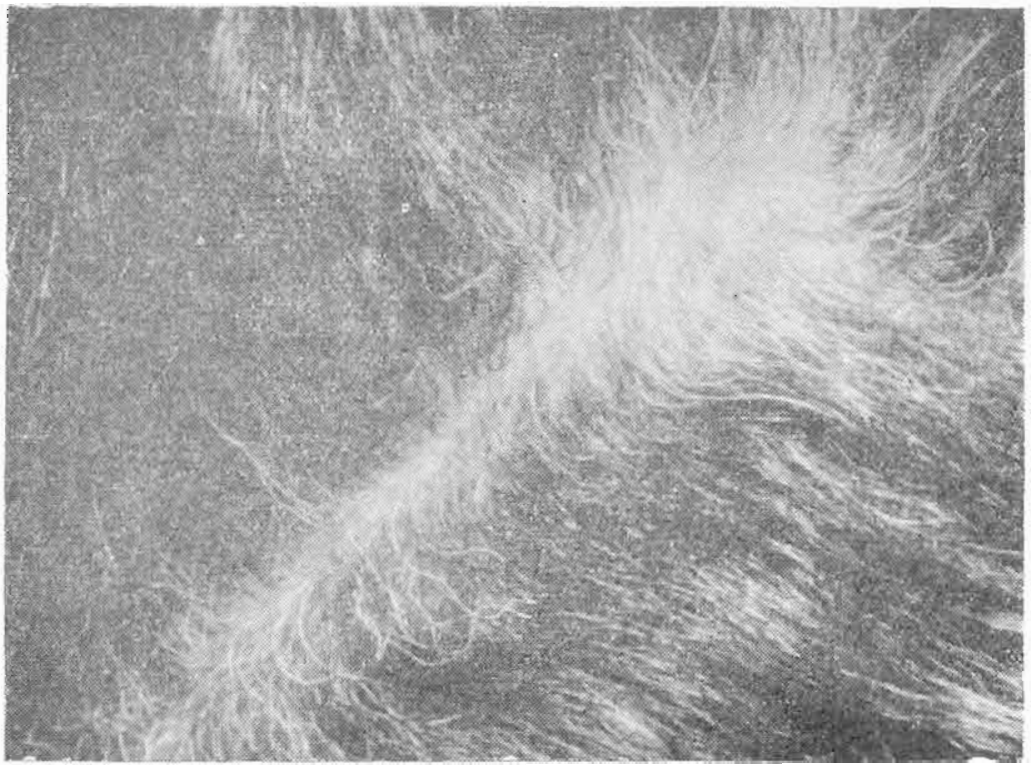

Foto Ni 3.- Se aprecio alopecia y poliosis.

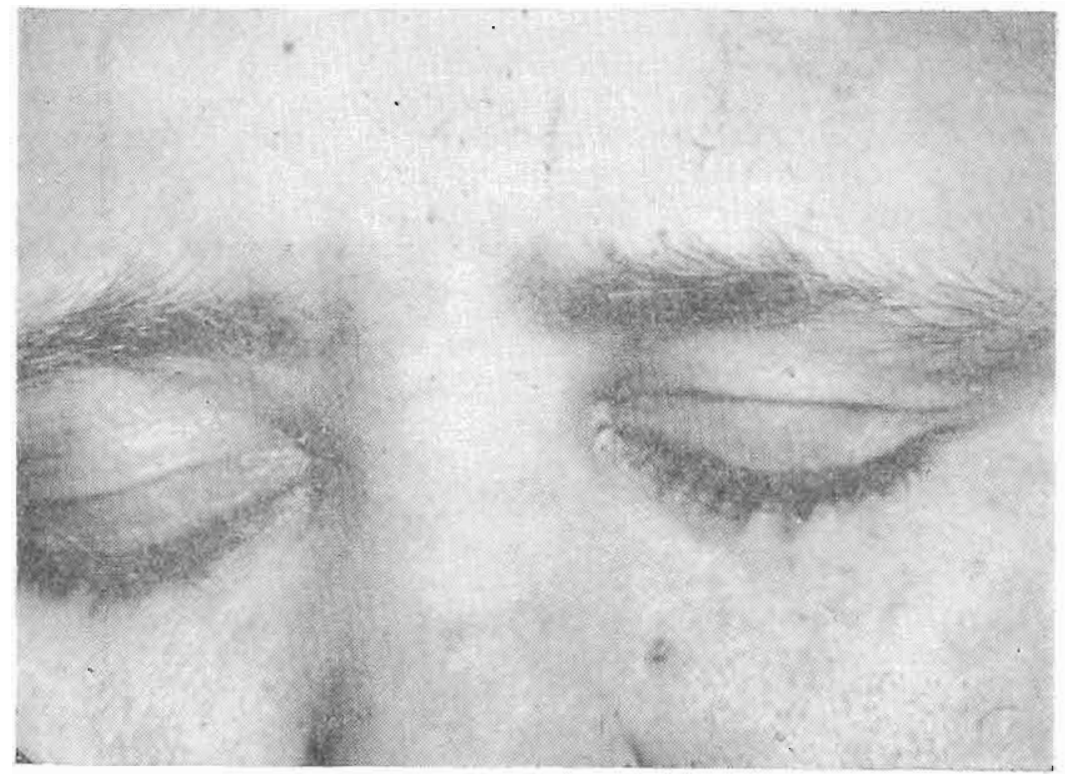

Foto Ne 4,- Polioșiș dẹ cejoș, 
ban casi todo el día, sin fiebre, rigidez nucal, vómito o síntomas visuales. Estos dolores de cabeza no se incrementaban con la tos o con los movimientos de la cabeza. Dos semanas antes de iniciar sus síntomas la paciente fué vista por un otorrinolaringólogo. Entre el 11 y el 19 de Agosto se le extrajo piezas dentarias por absceso, una de las cuales dejó una fístula buco-antral. Cinco días después notó apreciable disminución de la agudeza visual en ojo derecho, con visión de cuerpos flotantes e inyección del globo ocular. El examen neurológico en Agosto 30 fué aparentemerte negativo y lo mismo el E. E. G.

Categóricamente niega úlceras recurrentes en la boca, en los genitales, sordera, tinitus o artritis.

Historla Familiar. - Padre muerto de carcinoma en el hígado. Madre es diabética. Esposo: vivo y sano. Hijos: 2 vivos y sanos.

Antecedentes Personales Patológicos.- Paciente refiere haber tenido fiebre reumática a la edad de 11 años sin dejar residuo de enfermedad cardíaca - cualquier otra sintomatología. No hay historia de enfermedad alérgica. Paciente no fuma ni usa bebidas alcohólicas. Su peso ha estado estable.

Examen Físico.- Paciente bien desarrollada, bien nutrida, alerta y obviamente tensa. Fuera del efecto de su tensión, su memoria, su actitud, y sus tests de retención se encuentran dentro de límites normales. Piel normal y no se encontraba adenopatías significantes. Visión en O.D. 20/80 y O.S. 20/20. Habia un escotoma central en el campo visual derecho. La perimetría y los campos visuales se encontraban normales en el izquierdo con la única salvedad del discreto agrandamiento del punto ciego. La tensión en O.D. en $7.1 \mathrm{~mm}$. de Hg. y O.S. $8.5 \mathrm{~mm}$. Los M.E.O. eran normales y coordinados. Pupilas iguales y regulares con buenas reacciones a la luz y acomodación. A la lámpara de hendidura y en forma bilateral se apreciaba queratitis precipitadas, miliares, difusamente. Habia también células en el acuoso y su contenido proteico incrementado. El examen de fondo de ojo mostraba que ambos discos ópticos se hallaban difusamente hiperémicos. La retina y el segmento posterior edematosos y la presencia de estrella macular en ambos ojos; las venas distendidas con vigorosa pulsación venosa podían detectarse ante una suave presión al globo derecho. No producíamos lo mismo en el izquierdo. No pudimos observar hemorragia. El resto del examen clínico fué esencialmente normal.

Examen de Laboratorio.- Serologia negativa. Heces negativa para huevos y parásitos. Hemoglobina $14 \mathrm{gr}$. Hematocrito 40. Leucocitos en varias ocasiones se encontró entre 4,500 y 5,000. 57 polimorfonucleares. 32 pequeños linfocitos. 2 grandes linfocitos. 7 monocitos. Urograma normal. Velocidad de sedimentación $36 \mathrm{~mm}$. corregida. Glucosa 90. Nitrógeno no proteico 37 . Sodio 144. Potasio 4.1. Cloro 104. CO2 24.6. Calcio 9.3. Fósforo 5.3. Proteínas totales 7.6. A/G 4.1/3.5. Colesterol 243. Se realizaron 3 punciones lumbares entre el 10 de Setiembre y 3 de Octubre; todas revelaron iguales hallazgos. La presión inicial y final siempre fué normal. Su examen serológico fué negativo y el oro coloidal falló en demostrar alteraciones en su curva. La cuantía proteica de L.C.R. en las tres opłrtunidadés se encontraba entre 60 y 70 mm. La glucosa fué normal. Las preparacionęs de tinta china en las tres opor- 
tunidades también normal. El recuento celular de líquido fué 108,34 y 56 respectivamente, todos eran leucocitos. Los cultivos para hongos fueron negativos, digase lo mismo para tuberculosis. La investigación con pruebas cutáneas de Uveitis mostró negativo en lo referente a las reacciones de alfa estreptococo; positivo $2-3$ + a todos los estreptococos beta hemolíticos. $3+$ a la tuberculina $1 / 100$ a las 48 horas.

Radiografía de cráneo y Tórax normales. A su ingreso al Hospital se inició tratamiento con gotas de esteroides. El examen otorrinolaringológico mostró sinusitis maxilar con drenaje de pus procedente de la fístula buco-antral derecha. El 13 de Setiembre fué intervenido, se realizó un Caldwell-Luc y sutura de la fístula. El examen patológico mostró sinusitis crónica con reacción granulomatosa. No había hongos o bacilos ácidos resistentes. La consulta neurológica se inclinó como una enfermedad de Harada. A la paciente se le dió antibiótico de amplio espectro para su sinusitis.

Para Octubre $1^{0}$ su visión con agujero estenoipeico estaba en O.D. en 20/40 y O.S 20/25 no había células o proteínas en la cámara anterior. Se apreciaba algunas células en el vitreous en ambos ojos. Persistía el edema retinal sin separación de ella. El 6 de Octubre se implantó tratamiento con Decadrón. Diez dias después su visión en 20/25 y 20/20. La tención 20.6 en ambos ajos. Iba disminuyendo el edema peripapilar de ambos ojos.

Fué dada de alta el 18 de Octubre con instrucciones de continuar el Decadrón 0.25 y dos veces al día. Fué descontinuado las gotas oculares de esteroides. Su visión en $20 / 25$ y $20 / 20$ respectivamente. La biomicroscopía revelaba que la cámara anterior se encontraba libre de proceso inflamatorio y sólo en forma residual se veía queratitis precipitados en la cara posterior de la córnea. El cristalino y el vitreous estaban normales. La borrosidad de las pupilas de ambos ojos había disminuído marcadamente, sin embargo, los puntos ciegos persistían aumentados. La perimetría era normal.

El $1^{9}$ de Noviembre la paciente fué vista en Consultorio encontrándose su visión en O.U. 20/20. No habla papiledema. La tensión fué normal. Sólo se apreciaba una que otra queratitis precipitada. Pupilas simétricas, iguales y que reaccionaban a la luz y acomodación. El cristalino claro. No existía evidencia de exudados o hemorragias en ambos ojos. Se aconsejó disminuir el decadrón en forma gradual hasta descontinuarla en periodo de una semana.

El 9 de Febrero de 1959 la visión persistía 20/20 en O.U. El balance muscular era normal, anexos y tensión también normal. La lámpara de hendidura sólo reveló una o dos queratitis prẹcipitada en O.D. El examen del fondo de ojo mostró normalidad a lo referẹte a los nervios ópticos. Los vasos sanguíneos no mostrahan alteración. No herrorragias, exudados que pudiesen ser observados. La perimetría en los campos visuales normales.

EI 4 de Agosto de 1959 fué readmiticia para revaluación con referencia a sus ataques recurrentes de ansiedad. Su agudeza visual continuaba en 20/20. La lámpara de hendidura mostraba en ambos iris nódulos de Busacca, no existía células a contenido proteico en la cámara anterior. Dos grandes queratitis precipitadas en la córnea derecha. El cristalino y el vitreo continuaban claros. Detalles del estudio del segmento posterior no revelaban patología. 
Continuaba igual al previo examen. El L. C. R. y el examen neurológico dentro de límites normales.

CASO No 4.- Paciente de 30 años de edad, que es admitida al Hospital en Noviembre de 1957 por disminución de la agudeza visual y doior ocular bilateral.

Enfermedad Actual.- En Julio de 1957 con la visión considerablemente borrosa, ambos ojos rojos y audición considerableniente disminuída. Días después fué vista por colega quien indicó gotas oculares $e$ inyecciones intramusculares. 6 días después su visión continuaba igual pero su audición había mejorado. Fué admitida al Hospital; cuando se realizó investigaciones y se le informó tener desprendimiento de retina. Había recibido ACTH y Meticorten. Cuando fué dada de alta si visión había mejorado. En Setiembre de 1957, 10 semanas después de iniciada la enfermedad, estando asintomática, notó que el color del pelo. de la cabeza, cejas y pestañas se tornaban blanco. Notó descoloración de la piel, del pecho, brazo y caída de pelo. Continuó bien hasta Noviembre en que los síntomas regresan.

Antecedentes personales: Patológicos e historia familiar.- Sin importancia.

Examen Físico. - Mostró paciente femenina, obesa, negra bien desarrollada. Tenía en forma moderada canas en el pelo de la cabeza, cejas y pestañas. Se encontraba unas pequeñas áreas blancas en la parte anterior derecha del tórax y otra en el antebrazo derecho de $14 \times 17 \mathrm{~cm}$. Oídos: canales auditorios externos permeables, membrana timpánica intacta y de aspecto normal. Su visión se encontraba 20/70 - 2 sin corrección y 20/70 con corrección. En el ojo izquierdo de $20 / 200$ corregible a 20/70. Reacción ciliar bilateral. Cámaras anteriores de profundidad normal, mostrando $3+$ de fenómeno de Tindal. Las pupilas dilatadas mostrando sinequias posteriores rotas en ambos ojos. La sensibilidad corneal normal. Los M.E.O. normales. La tensión ocular en 14.6 en ambos ojos. Campos visuales normales.

El resto del examen físico incluyendo examen neurológico fué negativo.

La paciente fué dada de alta manteniéndose con ACTH, más midriáticos y esteroides local. Entonces su visión estaba en 20/20-2 en O.D. y 20/30 en O.S. sin corrección. Los audicgramas fueron normales. Frecuentemente fué vista en el consultorio por espacio de 3 meses donde no mostró evidencia de inflamación. Sin emkargo, en Junio 9 de 1958 regresó con severo dolor ocular y ojos rojos. Habla descontinuado todo el tratamiento hacía 2 semanas. Su visión estaba en $20 / 50$ en O.U. con y sin corrección. Era presente congestión ciliar y conjuntival. La tensión fué normal. Ambas córneas, opacas con considerable cantidad de queratitis precipitada. $3+$ de contenido proteico en O.U. pupilas pequeñas, fijas, se forzó dilatación con atropina y neosinefrina con lo cual pudo romperse sinequías posteriores. Esteroides nuevamente fueron indicadas. En su visita de retorno se observó abundante queratitis precipitada y abundante pigmento en la cara anterior del cristalino, estos hallazgos de mayor cuantía en el ojo izquierdo. Cortone suspensión local cada 2 horas se indicó. Días después se encontraba asintomática, los ojos mostraban menos inflamación y algunas células sólo en el ojo izquierdo. Cuando fué exa- 
minada en Febrero de 1959 su visión era mejorada a 20/20 en O.D. y 20/40 en O.S. No habian cambios en el aspecto de sus pestañas y cejas. En Marzo de 1959 su visión era de 20/20 en ambos ojos y continuaba con esteroides por vía oral aparte de midriáticos y cortone local. En Julio 1959 su visión continuaba igual. No había signos de inflamación en ambos ojos. Los fondos oculares mostraban discos y máculas normales. En la periferia de las retinas se apreciaba pequeños miliares exudados, blancos, amarillentos. En Setiembre de 1959 la terapia sistémica fué descontinuada pero, continuaba con Cortone y Atropina, su visión era mejorada de 20/20. Creía que las áreas de vitiligo en el tórax y en el brazo no habían cambiado de aspecto o tamaño. La decoloración de las pestañas y cejas continuaba igual; sin embargo había recobrado el pelo de la cabeza que había perdido y no aparecía tal como hacia un año.

En Marzo de 1960 su visión era normal y los hallazgos oculares no se habían modificado.

\section{RESUM $E N$}

Se reportan tres casos de la enfermedad de Harada y un caso del síndrome de Vogt-Koyanagi. Todos estos casos exhiben las características de esta entidad. Todos los casos fueron tratados con Cortisona sistémica y tópica, la cual parece ser de utilidad. Excelentes resultados (recuperación de la visión central y periférica), fueron obtenidos en los pacientes presentados. La única complicación en lo referente a la terapia fué un episodio aguaco de psicosis en el paciente No 3 que sobrevino luego de iniensa administración de Cortisona; ésta desapareció completamente 3 semanas después de disminución gradual de la droga.

Ha sido reportado que la enfermedad de Harada y el sindrome de Vogit-Koyanagi se presentan en pacientes de alta pigmentación. Es interesante omotar que 2 de los cuatro casos presentados eran en personas blancas.

La revisión de la literatura revela que la enfermedad es esporádica, sin aparente relación con las estaciones o con el área geográfica.

Se sugiere un nuevo término que tipifique la evolución clínica: Sindrome encefalo-uveo-dermatosis.

\section{B I B L I O G R A F I A}

Cordes, F. C. Harada Disease treated with Cortisone. Report of a typical case. Am. J. of Ophth. Vol. 39 April 1955 N. Y. part. I 499-509.

Bruno, M. and Mcpherson S. D. Harada's Disease Report of four cases. Amer. J. of Ophth. 32-513-522. April. 1949. 
Cowper A. R. Harada's Disease and Vogt-Koyanagi Syndrome Arch Ophth. 45-367-376. 1951.

Farnarier G. and Mouren P. Meningo-Uveitis. Rev. d'Oto-Neuro-Opht. 22-39-41. 1950.

Bessiere, E. and Arcelle L. Acute Lynphocytic-crytogenic-uveomeningitis and the Disease of Harada. Arch-Opht. 5-344-348. 1945.

Charmis Y. Maladie of Harada. Bull Soc. Hellen Ophth 18-53-54. 1951.

Robison D. Harley. Lt. Col (M.C.) and Erling S. Wedding Capl. (M.C.). Am. Jour. Opht. May 1946. Vol. 29. N.S. 524-535.

Reed, H. \& Lindsay A. The Uveo-Encephalic Syndrome. Vogt-Koyanagi-Harada Disease. Canadian Medical Assoc. Journal Sept. 1959. Vol. 79

No 6 451-459.

Rados, A. \& Neward, N. Bilateral Uveitis Associated with Detachment of the Retina. (Harada's Disease). Arch of Ophth.

Stadnik, J. R. Mc Fadden, H. W. Harada's Disease. A Case report. Amer. Journal of Ophth. August 1954. Vol. 38. 232-234.

Vogt. A. Rruzeitiges Ergraunen der Zilien und Bemerkungen uber den Sogenannten plotzichen Eintritt Diesser Veranderung, Klim. Monatsbl. f. Augenh. 44: 228, 1906.

Koyanagi, Y Dysakusis, Alopesia and Poliosis bei Schwerer uveitis nicht tramatischen Ursprungs, Klin Monatsbl. f. Augenth, 82: 194, 1929.

Carrasquillo. H. F. Uveitis with poliosis, vitiligo, alopesia and dysacusia (Vogt-Koyanagi Synarome), Arch. Ophth, 28: 385, 1942.

Ogawa, U. Ueber die patologische Anatomie der sog. Idiopathischen Uveitis mit Dysakusis und Poliosis, Acta Soc. Aphth. Jap. 38: 1005, 1934. 